\title{
Adaption of Knowledge and Participation of Stakeholders in Three Public Health Interventions at Local Government Level in Denmark
}

\author{
Maja Bertram $^{1^{*}}$, Anne Wiechmann ${ }^{2}$, Arja R Aro ${ }^{1}$ and Gabriel Gulis ${ }^{1}$ \\ ${ }^{1}$ Unit for Health Promotion Research, Institute of Public Health, University of Southern Denmark, Esbjerg, Denmark \\ ${ }^{2}$ Department of Health and Nursing, HFH · Hamburger Fern-Hochschule University of Applied Science, Hamburg, Germany
}

\section{Abstract}

Background: When implementing public health interventions in practice, it is recommended to use research evidence and to include relevant stakeholders. This should ensure effective interventions but it can be challenging. This study investigates the use of knowledge and inclusion of stakeholders in three different public health interventions at the local government level in Denmark and discusses strategies for future improvements in the use of research evidence.

Method: Based on a previous assessment of all public health interventions in Varde Municipality using the European Community Health Promotion Indicator Development Model (EUHPID model), three different types of interventions (one Health Promotion, one Health Protection, and one Disease Prevention) were chosen for a case study analysis. The data consisted of document reviews and interviews. Data were analysed by content analysis using a framework for Evidence Based Practice as a guiding tool. Discussion of strategies for future improvements was based on experiences from previous studies.

Results: In the Health Promotion and Disease Prevention interventions, knowledge of community characteristics and knowledge based on practitioners' expertise were the most applied types of knowledge. In the Health Protection intervention, evidence from research was also used. Various stakeholders were included in all interventions. Barriers for the use of research evidence were lack of access to reported research, lack of time and competences to identify, adapt and apply the most relevant research evidence. The perceived facilitators for using evidence from research were access to summaries of research results or guidelines based on research and collaboration with researchers.

Conclusion: Very limited knowledge on how to improve the use of research evidence in such interventions exists, however it seems like an active collaboration between research and practice is a promising strategy. There is a need for more research on this topic taking the role of various stakeholders into account.

\section{Publication History:}

Received: June 28, 2016

Accepted: August 14, 2016

Published: August 16, 2016

\section{Keywords:}

Disease prevention, Evidence, health policy, Health promotion, Health protection, Public health, Stakeholders

\section{Introduction}

It is well known that the use of research evidence in working with public health interventions in practice is a challenge [1-6]. A study of evidence use in Danish municipalities confirms this [7]. According to the literature, the use of research evidence in local public health work takes place in real life context of political and other societal priorities and activities [8-10]. This context makes it complicated to balance the inclusion of research evidence and other sources of relevant knowledge. Furthermore, it is shown to be difficult for local public health planners and policy makers to identify and apply the relevant research evidence in their daily work [7].

Local public health interventions aiming at promoting and/or protecting health and preventing diseases need to be carried out in collaboration between and across sectors to be most effective [1114]. This means that stakeholders involved in the interventions are not limited to health sector; they include other local sectors such as transportation, environment and education, as well as nongovernmental organizations and private sector. Hence, research evidence and other relevant knowledge and information come from multiple sources $[8,15]$.

Satterfield et al (2009) have developed a framework for "Evidence Based Practice" (EBP) describing the types of knowledge that can be used in this kind of public health work (figure 1) [8]. The framework describes how policy making in public health work often takes place in the intersection of best available research evidence, population characteristics, needs, values, and preferences, and resources including practitioners' expertise. Furthermore, the framework emphasizes the various stakeholders that need to be involved in working evidence-informed with public health, since the different kinds of knowledge must be obtained from various stakeholders [8]. The EBP framework was applied as a guiding tool for the data collection and analysis in this study. Stakeholders were defined as people involved in the intervention processes both from inside and outside of the municipality organization.

Within three months during 2009 a mapping of all public health interventions in Varde Municipality, Denmark was carried out. Based on The European Community Health Promotion Indicator Development Model (EUHPID model) [16] and specially developed categorization criteria, all interventions were assessed and categorized into the types "Health Promotion", "Health Protection", and "Disease Prevention" [17]. To learn more about the use of knowledge and inclusion of stakeholders within these different kinds of public health interventions, one intervention from each category were used as cases for analysis in this study.

*Corresponding Author: Dr Maja Bertram, Unit for Health Promotion Research, Institute of Public Health, University of Southern Denmark, Niels Bohrs Vej 9 Esbjerg 6700, Denmark, Tel: +45 6550 4268; E-mail: mbertram@health.sdu.dk

Citation: Bertram M, Wiechmann A, Aro AR, Gulis G (2016) Adaption of Knowledge and Participation of Stakeholders in Three Public Health Interventions at Local Government Level in Denmark. Int J Community Fam Med 1: 115. doi: http://dx.doi.org/10.15344/ijcfm/2016/115

Copyright: ( $) 2016$ Bertram. This is an open-access article distributed under the terms of the Creative Commons Attribution License, which permits unrestricted use, distribution, and reproduction in any medium, provided the original author and source are credited. 
Citation: Bertram M, Wiechmann A, Aro AR, Gulis G (2016) Adaption of Knowledge and Participation of Stakeholders in Three Public Health Interventions at Local Government Level in Denmark. Int J Community Fam Med 1: 115. doi: http://dx.doi.org/10.15344/ijcfm/2016/115

Page 2 of 6

The aim of this study was to investigate the use of knowledge and inclusion of stakeholders in three different types of public health interventions at local government level in Denmark, based on the framework for EBP by Satterfield et al. [8]. With starting point in this investigation, the secondary aim was to discuss strategies for facilitating the use of best available research evidence in combination with the other types of knowledge provided by the included stakeholders.

\section{Materials \& Method}

\section{Study site}

Varde municipality in Denmark was chosen as study site based on the fact that the previous assessment of public health interventions was performed in this municipality [17]. The Municipality carries out public health work based on an intersectoral health policy. The main objective of this health policy is to provide a framework for improving health and quality of life and to make the "healthy choice the easy choice" for all citizens. The policy suggests intersectoral action as a main approach for doing interventions, as recommended by the Adelaide Statement [11]. The priority areas of the policy are related to non-communicable diseases and point out specific priority populations such as children and youth, elderly, ethnic minority groups, persons with disabilities and persons with mental health conditions.

\section{Identification of interventions}

Based on the previous assessment of all public health interventions [17], the following criteria were used to select interventions:

1. One intervention from each category ("Health Promotion", "Health Protection", and "Disease Prevention") should be chosen for the analysis (to ensure for inclusion of each type of public health interventions).

2. The length of the intervention should be more than one month (to ensure for a certain amount of intervention content).

3. The intervention should have a potential for intersectoral collaboration (to ensure for the possibility of inclusion of different stakeholders).

The list of all public health interventions $(n=154)$ was reviewed using these criteria. In the Health Promotion category three interventions (out of 88) met the criteria; in the Health Protection category one intervention (out of 15) met the criteria; and in the Disease Prevention category two interventions (out of 51) met the criteria. From this, three interventions with different aims and targets groups were chosen for the analysis to strengthen the possibility of getting diversity in the results. It was decided only to choose one intervention from each category due to pragmatic reasons of capacity. The following interventions were chosen for the analysis:

- Health Promotion: "Time out"; an intervention aiming at improving well-being among youngsters

- Health Protection: “Traffic Safety Plan"; an intervention aiming at providing a safe traffic environment,

- Disease Prevention: "Step by Step"; an intervention aiming at preventing diseases among overweight persons via exercise and nutrition guidance.

\section{Analysis tool}

Based on a framework for EBP [8], following items were used to guide the analysis.

\section{Document review:}

1. Description of the interventions' contents including aims, intervention periods, methods and evaluations

2. Indications of use of best available research evidence

3. Indications of use of population characteristics, state, needs, values, and preferences

4. Indications of use of resources including practitioner's expertise

5. Indications of inclusion of various stakeholders

\section{Interviews}

1. Discussion of the results from document review and any supplementing information

2. Discussion of barriers and facilitators for using the best available research evidence in the working with the interventions.

\section{Data collection and analysis}

Using the municipality's internal documents system, all relevant documents on the three interventions were identified and filed. These included meeting minutes, working papers and intervention plans. The documents were analysed using the analysis tool, and all relevant information was marked. This documents analysis was supported by interviews with key persons (four in total) involved in the interventions. During the interviews, findings from the document analysis were discussed and further elaborated. Moreover, possible issues not presented in documents were uncovered.

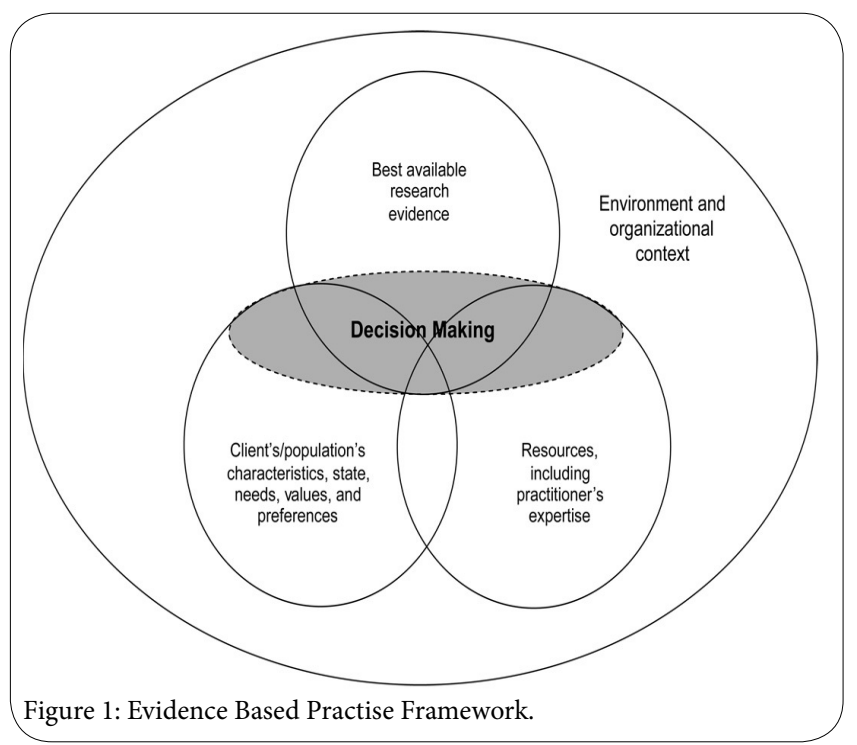

Results

\section{Description of interventions}

Table 1 explains the aims, intervention periods, methods and evaluation plans for the three interventions. Given the fact that the interventions were of various types, these contents of the interventions were also very different. The Health Promotion intervention aimed at empowering a large group of youngsters to gain control over various 
Citation: Bertram M, Wiechmann A, Aro AR, Gulis G (2016) Adaption of Knowledge and Participation of Stakeholders in Three Public Health Interventions at Local Government Level in Denmark. Int J Community Fam Med 1: 115. doi: http://dx.doi.org/10.15344/ijcfm/2016/115

Page 3 of 6

life situations through guidance by a social worker. The Health Protection intervention provided a plan for increasing traffic safety for all citizens in the municipality through physical changes in roads and paths. The Disease Prevention intervention aimed at helping a group of overweight persons to gain a healthier lifestyle through education in healthy diet and physical activity (both theory and practice), hence preventing them to get ill because of overweight. The effects of the interventions are ongoing; however a process evaluation has already been made of the Disease Prevention intervention. This process evaluation resulted in a decrease of mandatory gatherings and some gatherings were made voluntary instead, because the participants reported that not all gatherings were relevant for all of them. knowledge provided crucial input to how the two interventions were carried out. In the Health Promotion intervention the practitioner expertise mainly came from the social worker in charge of the intervention; her expertise was based on her professional education and on experiences in working with youngsters and the main issues associated to their wellbeing. Besides this other practitioners (an abuse consultant and a psychotherapist) had provided their professional expertise in the development of the intervention. In the Disease Prevention intervention the practitioner expertise came from the involved practitioners' experiences. This mainly included their professional education as nurses, dietician and physiotherapist and their respective experiences in working with obesity. In the Health

\begin{tabular}{|c|c|c|c|}
\hline & $\begin{array}{l}\text { Time Out } \\
\text { (Health Promotion) }\end{array}$ & $\begin{array}{l}\text { Traffic Safety Plan } \\
\text { (Health Protection) }\end{array}$ & $\begin{array}{l}\text { Step by Step } \\
\text { (Disease Prevention) }\end{array}$ \\
\hline Aim & $\begin{array}{l}\text { To provide free counselling (a "time } \\
\text { out") for high school students with } \\
\text { wellbeing issues. This can be related } \\
\text { to e.g. bullying, abuse, relationship to } \\
\text { parents/peers, general sadness. }\end{array}$ & $\begin{array}{l}\text { To reduce the number of deaths and } \\
\text { serious injuries on municipal roads and } \\
\text { paths by } 50 \% \text { in the year } 2017 \text { measured } \\
\text { relative to the average of deaths and } \\
\text { serious injuries during the period } 2005- \\
2007 \text {. This is equivalent to a maximum } \\
\text { of } 2 \text { killed and } 17 \text { seriously injured. }\end{array}$ & $\begin{array}{l}\text { To support overweight persons with a BMI } \geq \\
30 \text { to gain a healthier lifestyle. }\end{array}$ \\
\hline Intervention period & 2008-ongoing & $2009-2017$ & 2008-ongoing \\
\hline Method(s) & $\begin{array}{l}\text { A social worker is available via } \\
\text { mobile phone and agrees on meeting } \\
\text { with the students that contact her. } \\
\text { The social worker do counselling } \\
\text { based on the approach "appreciated } \\
\text { inquiry" and set up follow-up } \\
\text { meetings as required. }\end{array}$ & $\begin{array}{l}\text { The plan sets up objectives for working } \\
\text { with traffic safety in the municipality. It } \\
\text { defines focus areas for actions and target } \\
\text { groups to be prioritized. The methods } \\
\text { for improving traffic safety is through } \\
\text { physical changes in roads and paths (e.g. } \\
\text { speed bumps, pavements, roundabouts) }\end{array}$ & $\begin{array}{l}\text { An interdisciplinary team consisting of a } \\
\text { nurse, a dietician, and a physiotherapist } \\
\text { provides teaching modules on diet, exercise, } \\
\text { mental health, and motivation ( } 8 \text { sessions } \\
\text { in total - } 3 \text { of them voluntary). Decrease in } \\
\text { weight is not the main aim of the intervention; } \\
\text { instead focus is on gaining a healthier lifestyle. }\end{array}$ \\
\hline Evaluation & $\begin{array}{l}\text { No evaluation done or planned yet. } \\
\text { However, this is queried by the social } \\
\text { worker. }\end{array}$ & $\begin{array}{l}\text { No evaluation done yet, but according } \\
\text { to plans this will be done within the } \\
\text { intervention period and the Traffic } \\
\text { Safety plan will be revised accordingly. }\end{array}$ & $\begin{array}{l}\text { No evaluation of the effect of the intervention } \\
\text { done yet. Several evaluations of the } \\
\text { intervention process have been carried out } \\
\text { using information from participants. The } \\
\text { intervention has been revised accordingly. }\end{array}$ \\
\hline
\end{tabular}

Types of knowledge used in the three interventions

Table 2 summarises the types of knowledge used in the three different interventions. The only intervention with the use of best available research evidence was the Health Protection intervention. The evidence used was research on how to prevent traffic accidents by making physical changes in by the Danish Health and Medicines Authority were used as the basis information for developing the intervention $[18,19]$. These guidelines were developed based on evidence from research, so in that way evidence from research was indirectly used in this intervention as well.

In all three interventions knowledge about population characteristics was used. In the Health Promotion intervention, the information on wellbeing among high school students was derived from a national investigation and hence was not specific for the intervention's target group. In the Disease Prevention intervention, both national and local data on prevalence of obesity were used as justification for implementing the intervention. The Health Protection intervention used information on previous traffic accidents in the municipality to identify priority areas for actions. In this intervention, the needs and preferences of the population were also taken into account since statements from citizens concerning dangerous spots in traffic contributed to the prioritisation of focus areas and target groups in the Traffic Safety plan.

The use of practitioners' expertise was very significant in the Health Promotion and Disease Prevention intervention. In fact, this kind of roads and paths. In the Disease Prevention intervention, guidelines developed

Protection intervention there was no indication of use of practitioners' expertise, however in this intervention the available resources in relation to manpower and money were included in the intervention plan. This was not the case for the two other interventions.

Results from interviews showed that the perceived barriers and facilitators for using the best available research evidence was the same in all three types of public health interventions. The main barriers for this were lack of access to reported research, and lack of time and competences to identify, adapt and apply the most relevant research evidence. Furthermore, the informants stated that they found it difficult to determine how much emphasis to put on the message from research evidence if the messages from other sources of knowledge did not match this. The perceived facilitators for using evidence from research were access to summaries of research results or guidelines based on research, and collaboration with researchers.

\section{Involvement of stakeholders in the three interventions}

Table 3 displays the involved stakeholders in the three different public health interventions. In general, the interventions included various types of stakeholders from both inside the municipal organisation and outside this organisation.

\section{Discussion}

This case study including an analysis of three different types of public health interventions showed that various types of knowledge 
Citation: Bertram M, Wiechmann A, Aro AR, Gulis G (2016) Adaption of Knowledge and Participation of Stakeholders in Three Public Health Interventions at Local Government Level in Denmark. Int J Community Fam Med 1: 115. doi: http://dx.doi.org/10.15344/ijcfm/2016/115

Page 4 of 6

\begin{tabular}{|l|l|l|l|}
\hline $\begin{array}{l}\text { Best available } \\
\text { research evidence }\end{array}$ & $\begin{array}{l}\text { No indication of use of research } \\
\text { found. }\end{array}$ & $\begin{array}{l}\text { Use of research evidence about how to } \\
\text { prevent traffic accidents. }\end{array}$ & $\begin{array}{l}\text { No directly use of research, but use of generic } \\
\text { guidelines developed by national agencies } \\
\text { based on research. }\end{array}$ \\
\hline $\begin{array}{l}\text { Population } \\
\text { characteristics, } \\
\text { state, needs, values, } \\
\text { and preferences }\end{array}$ & $\begin{array}{l}\text { National data on wellbeing issues } \\
\text { among high school students. } \\
\text { (No specific data for the target } \\
\text { population) }\end{array}$ & $\begin{array}{l}\text { Local data on the prevalence of traffic } \\
\text { accidents. } \\
\text { Statements from citizens concerning } \\
\text { dangerous spots in local traffic settings. }\end{array}$ & $\begin{array}{l}\text { National and local data on the prevalence of } \\
\text { obesity. }\end{array}$ \\
\hline $\begin{array}{l}\text { Resources including } \\
\text { practitioner's } \\
\text { expertise }\end{array}$ & $\begin{array}{l}\text { No indication of use of available } \\
\text { monetary or manpower resources. } \\
\text { Major use of practitioner's } \\
\text { experiences. }\end{array}$ & $\begin{array}{l}\text { Use of information about available } \\
\text { monetary and manpower resources, but } \\
\text { no identification of use of experiences } \\
\text { by practitioners. }\end{array}$ & $\begin{array}{l}\text { No indication of use of available monetary or } \\
\text { manpower resources. } \\
\text { Maje of practitioners' experiences }\end{array}$ \\
\hline Table 2: Types of knowledge used. & \multicolumn{2}{|l}{} \\
\hline
\end{tabular}

\begin{tabular}{|c|c|c|c|}
\hline $\begin{array}{l}\text { Best available } \\
\text { research evidence }\end{array}$ & $\begin{array}{l}\text { Time Out } \\
\text { (Health Promotion) }\end{array}$ & $\begin{array}{l}\text { Traffic Safety Plan } \\
\text { (Health Protection) }\end{array}$ & Step by Step \\
\hline Target population & High school students & $\begin{array}{l}\text { Citizens, especially students in primary } \\
\text { schools and high schools }\end{array}$ & Enrolled participants \\
\hline Policy makers & $\begin{array}{l}\text { Committee for Social Affairs and } \\
\text { Health }\end{array}$ & $\begin{array}{l}\text { Committee for Planning and Technique } \\
\text { City Council } \\
\text { Development Board }\end{array}$ & Social Affairs and Health board \\
\hline $\begin{array}{l}\text { Sectors of } \\
\text { municipality }\end{array}$ & $\begin{array}{l}\text { Social Affairs and Health } \\
\text { Children and Youth }\end{array}$ & Planning, Culture and Technique & Social Affairs and Health \\
\hline $\begin{array}{l}\text { Non-governmental } \\
\text { organizations }\end{array}$ & - & - & Danish Heart Association \\
\hline Private sector & - & Consultancy company 'Carl Bro’ & - \\
\hline Others & $\begin{array}{l}\text { Teachers and student advisers at } \\
\text { high school }\end{array}$ & - & General Practitioners \\
\hline
\end{tabular}

and stakeholders are included in all intervention types as outlined by the EBP model [8]. However the Health Protection intervention was the only one with direct use of evidence from research. This might be because of an established tradition to use research evidence in preventing traffic accidents and the fact that research within this area is not questioned but instead understood as a solution to promote traffic safety. Though, this is only an assumption and no supporting evidence has been found in the literature.

In the Disease Prevention intervention, evidence from research was indirectly used via using general guidelines from national bodies based on results from research. The challenge connected to this is the fact that such guidelines can be out-dated; however in this study such a guideline seemed to be the reason for research evidence being included at all.

Based on the information from the informants, strategies for improving the use of research evidence needs to include actions in relation to dealing with challenges connected to lack of access, time, and competences to identify, adapt, and apply research evidence in combination with the knowledge provided by other relevant and included stakeholders.

Some studies have been carried out to deal with this issue [20,21]. Most of them suggest strategies that might be beneficial in relation to local public health interventions with inclusion of various types of knowledge and different stakeholders, as described in this study. Basically, the literature shows that to make an impact on the uptake of research evidence in working with public health interventions in practice, actions launched must be of an active character [20, 22]. This means that an active collaboration between research and practice needs to take place. Actions that seem to be effective are tailored, targeted, and timely and relevant messages from research to practice developed via an integration of practice needs and inter-professional collaboration as e.g. workshops with participation from both research and practice $[20,22-24]$. Furthermore, organizational changes to provide time for working with evidence from research in practice can enhance the use of research in public health interventions $[25,26]$. Actions that do not seem to have an impact on the uptake of research evidence in practice are of passive character. These includes e.g. to provide practice with printed information $[24,27,28]$ or to provide access to online research evidence resources [29].

Various stakeholders were involved in the three different public health interventions described in this study. For being able to include knowledge from the population in focus and the practitioners involved, these need to be included in the full policy process of working with the interventions [8]. This did not seem to be a problem in the cases analysed. Nevertheless, it was perceived to be a challenge to balance the knowledge derived from these sources and from research. The role of stakeholder inclusion in carrying out public health interventions based on a complex knowledge foundation is very limited. Some studies state the importance of stakeholder inclusion [17, 23-25, 30-32], and a few investigate the effect of e.g. carrying out a shared process of intervention development and reporting [23, 24]. However, no sustainable increase of the use of research evidence in practice has been reported $[23,24]$. 
Citation: Bertram M, Wiechmann A, Aro AR, Gulis G (2016) Adaption of Knowledge and Participation of Stakeholders in Three Public Health Interventions at Local Government Level in Denmark. Int J Community Fam Med 1: 115. doi: http://dx.doi.org/10.15344/ijcfm/2016/115

Page 5 of 6

When using these recommendations, it is important to take into account that most of the studies behind are conducted within a Health Care setting. Hence, the need for studies conducted in relation to Health Promotion, Health protection and Disease Preventions is prevalent.

\section{Strengths and Limitations of the Study}

This study was carried out by using case study method analysing three different types in public health interventions in one Danish municipality and interviewing a limited number of stakeholders. It can be questioned whether the results are applicable for other settings. Given the fact that the Danish municipalities are responsible for the same kind of tasks within public health, other Danish municipalities might work in the same way and experience the same challenges.

Despite these limitations, the study provides new knowledge about the use of different types of knowledge and inclusion of various stakeholders in three different types of public health interventions. Furthermore, the study provides information on the perceived challenges and facilitators for the use of research evidence. This can potentially add to future improvements in this regard, since the results can serve as an input to the already on-going research on how to improve evidence informed public health work emphasising the importance of stakeholder inclusion [33].

\section{Conclusion}

Based on a model for Evidence Based Practice [8], this study has investigated the use of different types of knowledge and inclusion of various stakeholders in three different types of public health interventions in a Danish municipality. The results showed that in Health Promotion and Disease Prevention interventions, knowledge of community characteristics and knowledge based on practitioners' expertise are the most applied types of knowledge. Furthermore, the results showed that various stakeholders are included in the intervention process, as suggested by the applied model. Very limited knowledge on how to improve the use of research evidence in such interventions exists; however, it seems like an active collaboration between research and practice is a promising strategy. There is a need for more research on this topic taking the role of various stakeholders in account.

\section{Competing Interests}

The author(s) declare that they have no competing interests.

\section{Author Contributions}

MB has carried out the study under supervision of GG. Hence, MB and GG are responsible for the conception and design, acquisition of data, analysis and interpretation of data. MB drafted the manuscript and AW, AA, and GG revised it critically for important intellectual content. All authors have approved the final version to be published.

\section{References}

1. Brownson RC, Fielding JE, Maylahn CM (2009) Evidence-based public health: a fundamental concept for public health practice. Annu Rev Public Health 30: 175-201.

2. Hanney SR, Gonzalez-Block MA, Buxton MJ, Kogan M (2003) The utilisation of health research in policy-making: concepts, examples and methods of assessment. Health Res Policy Syst 1: 2.
3. Higgins JW, Strange K, Scarr J, Pennock M, Barr V, et al. (2011) "It's a feel. That's what a lot of our evidence would consist of ": public health practitioners' perspectives on evidence. Eval Health Prof 34: 278-96.

4. Jansen M, van Oers HAM, Kok G, de Vries NK (2010) Public health: disconnections between policy, practice and research. Health Res Policy Syst 8: 37.

5. Orton L, Lloyd-Williams F, Taylor-Robinson D, O'Flaherty M, Capewell $S$ (2011) The use of research evidence in public health decision making processes: systematic review. PLoS One 6: e21704.

6. Hämäläinen RM, Aro AR, van de Goor I, Lau CJ, Jakobsen MW, et al. (2015) Exploring the use of research evidence in health-enhancing physical activity policies. Health Res Policy Syst 13: 43.

7. Larsen M, Gulis G, Pedersen KM (2012) Use of evidence in local public health work in Denmark. Int J Public Health 57: 477-483.

8. Satterfield JM, Spring B, Brownson RC, Mullen EJ, Newhouse RP, et al. (2009) Toward a transdisciplinary model of evidence-based practice. Milbank Q 87: 368-390.

9. Aro AR, Smith J, Dekker J (2008) Contextual evidence in clinical medicine and health promotion. Eur J Public Health 18: 548-549.

10. Dobrow MJ, Goel V, Upshur REG (2004) Evidence-based health policy: context and utilisation. Soc Sci Med 58: 207-217.

11. WHO and t.G.o.S. Australia (2010) The Adelaide Statement on Health in All Policies: moving towards a shared governance for health and well-being. Health Promotion International 25: 258-260.

12. Dahlgren GWM (1991) Policies and strategies to promotoe equity in health Institute for Future Studies: Stockholm.

13. Hyde $\mathrm{J}$ (2008) How to make the rhetoric of joined-up government really work. Aust New Zealand Health Policy 5: 22.

14. Puska $P$ (2007) Health in all policies. The European Journal of Public Health 17: 328-328.

15. Egan M, Bambra C, Petticrew M, Whitehead M (2009) Reviewing evidence on complex social interventions: appraising implementation in systematic reviews of the health effects of organisational-level workplace interventions. J Epidemiol Community Health, 63: 4-11.

16. Bauer G, Davies JK, Pelikan J (2006) The EUHPID Health Development Model for the classification of public health indicators. Health Promot Int 21: 153-159.

17. Larsen M, Pedersen HS, Davies JK, Gulis G (2013) Assessing public health intervention practices in a Danish municipality: applying criteria based on the European Community Health Promotion Indicator Development (EUHPID) model. Scand J Public Health 41: 778-784.

18. Danish Health Authority (2006) Metoder og redskaber til indsatser mod overvægt (Methods and tools for efforts against overweight).

19. Danish Health Authority (2003) Oplæg til national handlingsplan mod svær overvægt (Proposal for national action plan against obesity)

20. LaRocca R, Yost J, Dobbins M, Ciliska D, Butt M (2012) The effectiveness of knowledge translation strategies used in public health: a systematic review. BMC Public Health 12: 751.

21. Lavis JN, Oxman AD, Lewin S, Fretheim A (2009) Support Tools for evidence-informed health Policymaking (STP). Health Research Policy and Systems 7: 1-7.

22. Grimshaw JM, Eccles MP, Lavis JN, Hill SJ, Squires JE (2012) Knowledge translation of research findings. Implementation Science 7: 1-17.

23. Kothari A, Birch S, Charles C (2005) "Interaction" and research utilisation in health policies and programs: does it work? Health Policy 71: 117-125.

24. Gagliardi AR, Fraser N, Wright FC, Lemieux-Charles L, Davis D (2008) Fostering knowledge exchange between researchers and decisionmakers: exploring the effectiveness of a mixed-methods approach. Health Policy 86: 53-63.

25. Dobbins M, Jack S, Thomas H, Kothari A (2007) Public health decisionmakers' informational needs and preferences for receiving research evidence. Worldviews Evid Based Nurs 4: 156-63.

26. Kitson AL (2009) The need for systems change: reflections on knowledge translation and organizational change. J Adv Nurs 65: 217-228. 
Citation: Bertram M, Wiechmann A, Aro AR, Gulis G (2016) Adaption of Knowledge and Participation of Stakeholders in Three Public Health Interventions at Local Government Level in Denmark. Int J Community Fam Med 1: 115. doi: http://dx.doi.org/10.15344/ijcfm/2016/115

Page 6 of 6

27. Armstrong R, Doyle J, Lamb C, Waters E (2006) Multi-sectoral health promotion and public health: the role of evidence. J Public Health (Oxf) 28: $168-172$.

28. Di Noia J, Schwinn TM, Dastur ZA, Schinke SP (2003) The relative efficacy of pamphlets, CD-ROM, and the Internet for disseminating adolescent drug abuse prevention programs: an exploratory study. Prev Med 37: 646-53.

29. Buchan H, Lourey E, D'Este C, Fisher RS (2009) Effectiveness of strategies to encourage general practitioners to accept an offer of free access to online evidence-based information: a randomised controlled trial. Implement Sci 4: 68

30. Baker EA, Brownson RC, Dreisinger M, McIntosh LD, Karamehic-Muratovic A (2009) Examining the Role of Training in Evidence-Based Public Health: A Qualitative Study. Health Promot Pract 10: 342-348.

31. Baker R, Camosso-Stefinovic J, Gillies C, Shaw EJ, Cheater F, et al. (2010) Tailored interventions to overcome identified barriers to change: effects on professional practice and health care outcomes. Cochrane Database Syst Rev 17: CD005470.

32. Valente A, Castellani T, Larsen M, Aro AR (2014) Models and visions of science-policy interaction: Remarks from a Delphi study in Italy. Science and Public Policy 42: 228-241.

33. Aro AR, Bertram M, Hämäläinen RM, Van De Goor I, Skovgaard T et al. (2015) Integrating research evidence and physical activity policy makingREPOPA project. Health Promotion International 31: 430-439. 